\title{
Effect of Different Concentrations of Chitosan as Final Irrigating Solution on Smear Layer Removal and Calcium Ions Concentration
}

\author{
Huda I. Mostafa ${ }^{(1)}$, Mohsen N. El Deen ${ }^{(2)}$, Hagar A. EI Naby ${ }^{(3)}$
}

Codex : 63/1810

azhardentj@azhar.edu.eg

http://adjg.journals.ekb.eg

\section{KEYWORDS}

Chitosan, Irrigating Solution,

Smear Layer, Calcium Ions

Concentration.

\begin{abstract}
Purpose: This study was designed to evaluate the effect of different concentrations of chitosan as final rinse on removing smear layer using scanning electron microscope (SEM) and to quantify the calcium content using energy dispersive X-ray microanalyzer (EDX). Materials and Methods: Fifty extracted human single rooted premolars were selected and instrumented with Revo-S Ni-Ti rotary files. Samples were divided into 4 experimental groups according to the final rinse used and control group (10 samples each) where group I,II,II,IV were irrigated with $0.2 \%, 1 \%, 2 \%$ chitosan and EDTA respectively ,Group V (Control group): Va (5 samples) irrigated with sterile saline. $\mathrm{Vb}$ (5 samples) not prepared or received any treatment. Samples were grooved and spilt longitudinally and smear layer were evaluated using (SEM) at (coronal, middle and apical) levels and calcium content of intraradicular dentin was measured using (EDX) at middle level. Results: Regarding smear layer removal, at the coronal level, there was a statistically significant difference among the tested groups and the control group in the mean scores of smear layer, however, there was no statistical significant difference among the tested groups in the mean scores of smear layer .At the middle and apical thirds, the lowest mean score of smear layer was recorded in specimens treated with $2 \%$ chitosan with a statistical significant difference from specimens treated with $0.2 \%$ chitosan. However, there was no statistical significant difference in the mean smear layer scores among 1\% chitosan, 2\% chitosan and 17\% EDTA. Concerning calcium ion concentration there was no statistical significant difference among the tested groups. Conclusions: Chitosan was capable of adequately removing smear layer from intraradicular dentin when used as final rinse. The concentration of chitosan is influential in smear layer removal from intraradicular dentin, being more effective when used in $1 \%$ and $2 \%$ concentrations. Different concentrations of chitosan did not affect the calcium content of intraradicular dentin.
\end{abstract}

1. Demonstrator of Endodontics, Endodontic Department, Faculty of Dental Medicine for Girls, Al- Azhar University.

2. Professor of Endodontics, Endodontic Department, Faculty of Dental Medicine for Girls, Al -Azhar University

3. Associate Professor of Endodontics, Endodontic Department, Faculty of Dental Medicine for Girls, Al-Azhar University 


\section{INTRODUCTION}

The key objectives of endodontic therapy are elimination of microorganisms from the root canal system and prevention of reinfection. Cleaning and shaping are considered to be the most important and most demanding step. During this phase, dentin chips created by the action of endodontic instruments add to the remnants of organic material, forming a smear layer that adheres to the canal wall ${ }^{(1)}$. It has been shown that the smear layer may contain and harbor bacteria, preventing the canal from being disinfected, limit the penetration of intracanal disinfectants and sealers into dentinal tubules and interferes with a tight adaptation of root canal sealers to dentin walls. Therefore, the removal of smear layer is crucial for long-term success of root canal treatment ${ }^{(2)}$.

Removal of smear layer requires the use of irrigants that can dissolve both organic and inorganic components. Sodium hypochlorite $(\mathrm{NaOCl})$ is the most commonly employed irrigating solution due to its unique tissue dissolving property where it dissolves necrotic and vital organic tissue and its antibacterial activity. However, it does not exert any effect on the inorganic components of smear layer (3). Therefore, chelating agents (calcium complexing agents) such as Ethylenediaminetetra acetic acid (EDTA) is used with $\mathrm{NaOCl}$ solutions for smear layer removal ${ }^{(4)}$.

All the irrigation solutions at our disposable have their share of limitations. The search for an irrigant being more biocompatible than EDTA aiming at minimizing its harmful effect on periapical tissue, more effective in the apical third, more bactericidal and fungicidal without developing bacterial resistance and environmental concerns have also led researchers to seek alternative one. In addition EDTA is not originally found in nature and therefore considered to be pollutant. Therefore, herbal or natural products have become more popular today due to their high antimicrobial activity, biocompatibility, anti-inflammatory and anti-oxidant properties ${ }^{(5)}$.

Chitosan is a natural, cationic aminopolysaccharides copolymer of glucosamine and $\mathrm{N}$-acetylglucosamine obtained by the alkaline, partial deacetylation of chitin. It is the second most abundant natural polysaccharide and originates from shells of crustaceans.Chitosan has attracted attention in dental research because of its biocompatibility, biodegradability, bioadhesion and lack of toxicity. Moreover, it has a high chelating ability for various metal ions in acidic conditions. Owing to these properties, chitosan was applied as a chelating agent. Chitosan has become ecologically interesting because of its abundance in nature and low production cost ${ }^{(6-8)}$.

The effect of chitosan at different concentrations on the removal of the smear layer and on dentin structure after 3 and 5 min of application has been evaluated. The results showed that $0.2 \%$ chitosan for $3 \mathrm{~min}$ appeared to be efficient for removing the smear layer causing little erosion of dentin ${ }^{(9)}$. Also, the efficacy of $0.2 \%$ chitosan compared with different chelating agents(15\% EDTA, 10\% citric acid, $1 \%$ acetic acid ) in removal smear layer by scanning electron microscopy (SEM) after root canal instrumentation has been assessed. The results showed that $15 \%$ EDTA, $0.2 \%$ chitosan and $10 \%$ citric acid effectively removed smear layer from the middle and apical thirds of the root canal and $15 \%$ EDTA and $0.2 \%$ chitosan were associated with the greatest effect on root dentin demineralization, followed by $10 \%$ citric acid and $1 \%$ acetic acid ${ }^{(10)}$.

Smear layer removal after final irrigation with $17 \%$ EDTA, $1 \%$ citric acid, Biopure MTAD, and $0.2 \%$ chitosan solutions was compared. It has been concluded that final irrigation with $0.2 \%$ chitosan solution was more efficient in smear layer removal $^{(11)}$. Moreover, it has been reported that $2 \%$ chitosan, 4\% C-citrate, $10 \%$ CA presented the least amounts of smear layer, debris, and erosion among 
the experimental groups at the apical, middle, and coronal one thirds of the root canal with no statistically significant difference ${ }^{(12)}$.

Attempts to develop an efficient regimen for smear layer removal, urged the interest to evaluate the effect of different concentrations of chitosan on smear layer removal and comparing the results with a well established one.

\section{MATERIALS AND METHODS}

Fifty freshly extracted human single rooted premolars with completely formed roots and no evidence of cracks or fractures were selected. The teeth were rinsed in tap water to remove blood, tissue and debris and placed in sodium hypochlorite $2.6 \%$ for 1 hour and stored in saline solution until use. Each tooth was decapitated at the cementoenamel junction using diamond disc under constant water cooling and the root length was standardized to be $16 \mathrm{~mm}$. The working lengths were measured by subtracting $1 \mathrm{~mm}$ from lengths when the tips of \#10 K-files became observed at the apical foramina. Root apices were closed with sticky wax to simulate the closed-end model.

Preparation of $0.2 \%, 1 \%$ and $2 \%$ chitosan solutions was performed using $0.2 \mathrm{~g}, 1 \mathrm{~g}$ and $2 \mathrm{~g}$ of chitosan (90\% degree of deacetylation) respectively, each diluted in $100 \mathrm{ml}$ of $1 \%$ acetic acid, and the mixture was stirred for $2 \mathrm{~h}$ using a magnetic stirrer ${ }^{(9)}$. The solution was used within one week after preparation and saved in the refrigerator. The $\mathrm{pH}$ of each solution was determined by using Thermo Scientific Orion 2-star benchtop $\mathrm{pH}$ meter, where the $\mathrm{pH}$ of $0.2 \%, 1 \%$ and $2 \%$ chitosan solutions where $4.6,4$ and 3.25 respectively.

Revo-S Ni-Ti rotary files were used in a crowndown manner for root canal preparation with a 16:1 reduction handpiece that was powered by a torquecontrolled electric motor; at a rotational speed of $300 \mathrm{rpm}$ and a torque-control of $0.8 \mathrm{~N} / \mathrm{cm}$. Root canal preparation was done starting with $\mathrm{SC} 1$ file (\#
$25,0.06$ taper) which was used to $2 / 3$ of the working length and ended with AS 40(\# 40, 0.06 taper) which was used as master apical file.

After each instrument use, irrigation with 2 $\mathrm{ml}$ of freshly prepared $2.6 \%$ sodium hypochlorite $(\mathrm{NaOCl})$ solution for 1 minute dispensed through a 30 gauge side vent irrigating needle, where the needle was inserted as deep as possible into the root canal without binding. The total volume of $2.6 \%$ $\mathrm{NaOCl}$ irrigating solution used was $12 \mathrm{ml}$.

After root canal preparation, the samples were divided into 4 experimental groups (I,II,III,IV) according to the final rinse used and control group (V) (10 samples each): Group I: irrigated with $0.2 \%$ chitosan. Group II: irrigated with $1 \%$ chitosan. Group III: irrigated with $2 \%$ chitosan. Group IV: irrigated with $17 \%$ EDTA. The final rinse was done with $5 \mathrm{ml}$ of each solution for 3 minutes, dispensed through a 30 gauge side vent irrigating needle or 24 gauge needle (for group III [2\% chitosan]), where the needle was inserted as deep as possible into the root canal without binding, then the canals were irrigated with $10 \mathrm{ml}$ distilled water and dried with paper points. Group V: Control group which was divided into:(Va): five samples were irrigated with sterile saline. ( $\mathrm{Vb}$ ): five samples were neither prepared nor received any treatment to assess the calcium content with energy dispersive X-ray microanalyzer (EDX).

All samples were grooved longitudinally on the external surface (buccal and lingual) with diamond disc, avoiding penetration of the root canals. The samples were then carefully split with a hammer and chisel into two halves. Photomicrographs were taken under magnification (X 4000) for smear layer scores at the coronal, middle and apical thirds of the root canals and analyzed by means of numerical evaluation scores by Hülsmann et al (1997) ${ }^{(13)}$ as following:

Score 1: No smear layer and patent dentinal tubules. Score 2: Small amount of smear layer, some 
open dentinal tubules. Score 3: Homogenous smear layer covering the root canal wall, only few open dentinal tubules. Score 4: The entire root canal wall covered with a homogenous smear layer, no open dentinal tubules. Score 5: Heavy, non-homogenous smear layer covering the entire root canal wall.

The calcium content of intraradicular dentin of five samples from each experimental group (I,II,III,IV) and the samples of control group (Va, Vb) was measured by Energy Dispersive X-ray (EDX)at the middle level. Data were presented as mean and standard deviation (SD) values. For parametric data; one way ANOVA test was used to compare among the different groups. Tukey's post hoc test was used for pair-wise comparisons when ANOVA test was significant. Repeated measures ANOVA were used for comparison among the three levels in each group. The significance level was set at $\mathrm{P} \leq 0.05$.

\section{RESULTS}

\section{A. Smear layer removal results:}

\section{Comparison of smear layer scores among the tested groups at each level; (Table 1, Fig .1,2)}

At the coronal level, there was a statistically significant difference among the tested groups and the control group in the mean scores of smear layer $(\mathrm{P} \leq$ $0.05)$. The lowest mean score of smear layer was recorded in specimens treated with $1 \%$ chitosan. However, there was no statistical significant difference in the mean scores of smear layer produced by $0.2 \%$ chitosan, $1 \%$ chitosan, $2 \%$ chitosan and $17 \%$ EDTA.

Regarding the middle and apical thirds, there was a statistically significant difference among the tested groups in the mean scores of smear layer $(\mathrm{P} \leq$ $0.05)$. The lowest mean score of smear layer was recorded in specimens treated with $2 \%$ chitosan with a statistical significant difference from specimens treated with $0.2 \%$ chitosan. However, there was no statistical significant difference in the mean smear layer scores among $1 \%$ chitosan, $2 \%$ chitosan and $17 \%$ EDTA.

Table (1): Descriptive analysis of the smear layer scores at the coronal, middle, apical level of all tested groups.

\begin{tabular}{|c|c|c|c|c|c|c|c|c|c|c|c|}
\hline \multirow[b]{2}{*}{ Root level } & \multicolumn{2}{|c|}{$\begin{array}{c}\text { Group I } \\
(0.2 \% \text { Chitosan })\end{array}$} & \multicolumn{2}{|c|}{$\begin{array}{c}\text { Group II } \\
\text { (1\% Chitosan) }\end{array}$} & \multicolumn{2}{|c|}{$\begin{array}{c}\text { Group III } \\
\text { (2\% Chitosan) }\end{array}$} & \multicolumn{2}{|c|}{$\begin{array}{c}\text { Group IV } \\
\text { (17\% EDTA) }\end{array}$} & \multicolumn{2}{|c|}{$\begin{array}{c}\text { Group Va } \\
\text { saline (control) }\end{array}$} & \multirow{2}{*}{$P$-value } \\
\hline & Mean & SD & Mean & SD & Mean & SD & Mean & SD & Mean & SD & \\
\hline Coronal & $1.30^{\mathrm{aA}}$ & 0.48 & $1.20^{\mathrm{aA}}$ & 0.42 & $1.60^{\mathrm{aB}}$ & 0.52 & $1.30^{\mathrm{aA}}$ & 0.48 & $3.80^{\mathrm{bA}}$ & 0.84 & $0.000 *$ \\
\hline Middle & $1.70^{\mathrm{bA}}$ & 0.48 & $1.20^{\mathrm{aA}}$ & 0.42 & $1.10^{\mathrm{aA}}$ & 0.32 & $1.20^{\mathrm{aA}}$ & 0.63 & $4.00^{\mathrm{cA}}$ & 0.71 & $0.000 *$ \\
\hline Apical & $2.80^{\mathrm{bB}}$ & 0.92 & $1.80^{\mathrm{aB}}$ & 0.42 & $1.70^{\mathrm{aB}}$ & 0.48 & $2.20^{\mathrm{aB}}$ & 0.42 & $5.00^{\mathrm{cB}}$ & 0.00 & $0.000 *$ \\
\hline Overall & $1.93^{\mathrm{b}}$ & 0.38 & $1.4^{\mathrm{a}}$ & 0.31 & $1.47^{\mathrm{a}}$ & 0.28 & $1.57^{\mathrm{a}}$ & 0.39 & $4.27^{\mathrm{c}}$ & 0.37 & $0.000 *$ \\
\hline$P$-value & \multicolumn{2}{|c|}{$0.000 *$} & \multicolumn{2}{|c|}{$0.004 *$} & \multicolumn{2}{|c|}{$0.013^{*}$} & \multicolumn{2}{|c|}{$0.000 *$} & \multicolumn{2}{|c|}{$0.024 *$} & \\
\hline
\end{tabular}

*: Significant at $P \leq 0.05$.Different lower case letters within each row are statistically significantly different. Different upper case letters within each row are statistically significantly different. 


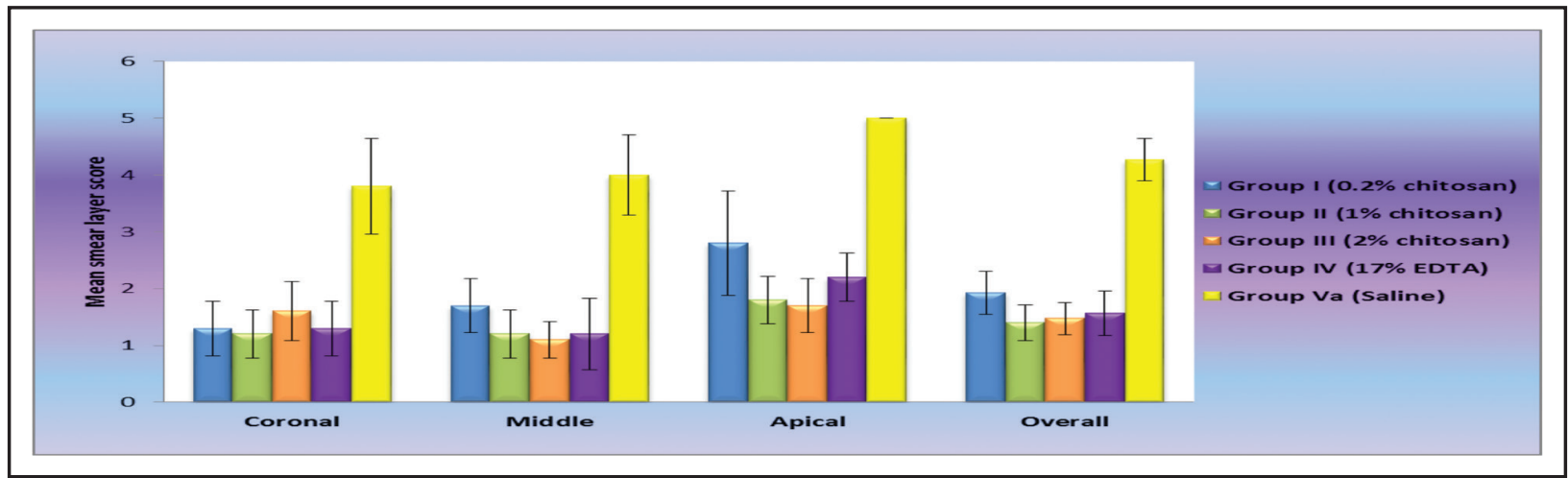

Fig. (1): A bar chart comparing the mean scores of smear layer and standard deviation among $0.2 \%$ chitosan, $1 \%$ chitosan, $2 \%$ chitosan, 17\% EDTA and saline groups at the coronal, middle and apical levels.
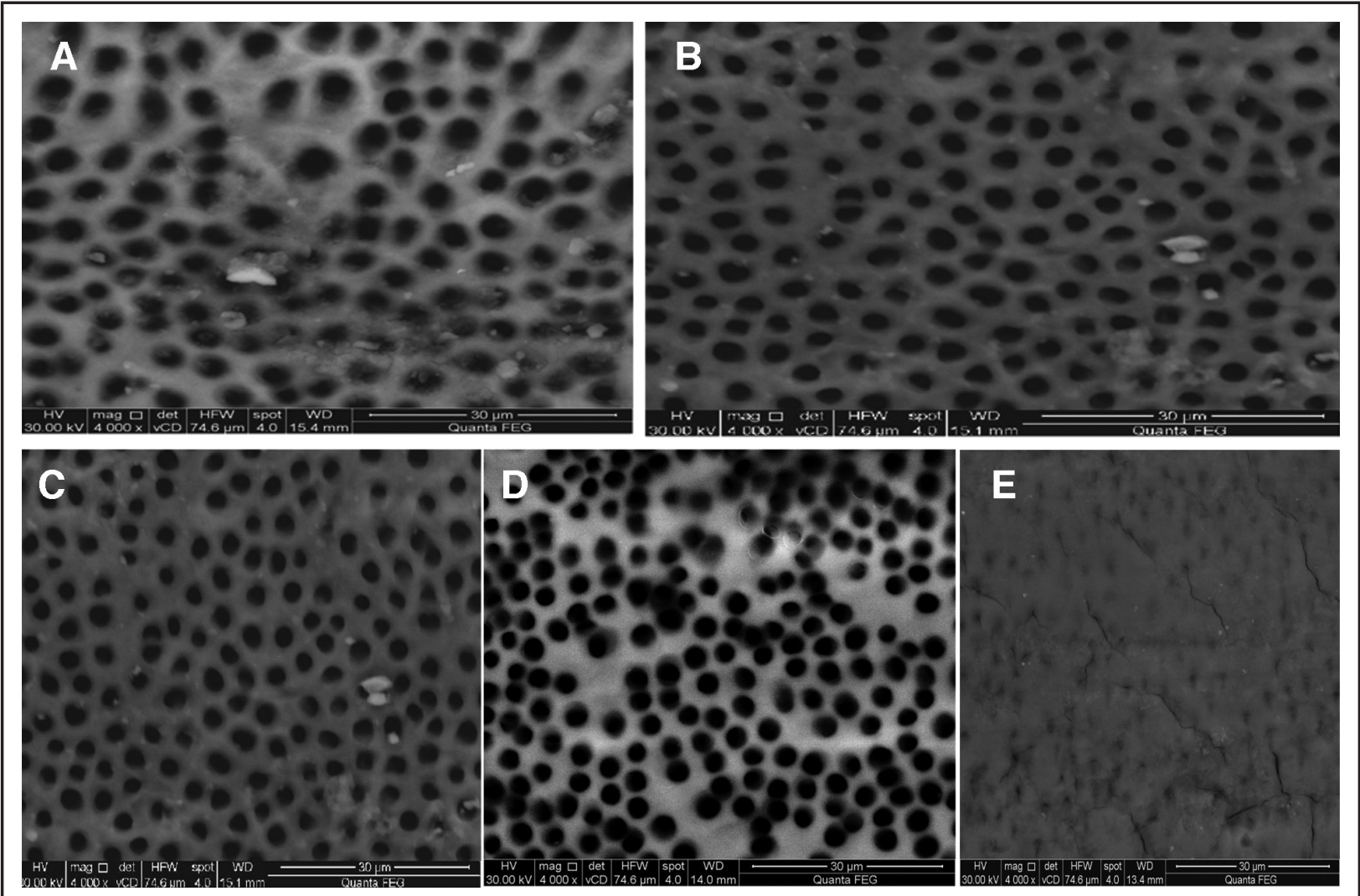

Fig. (2): A scanning photomicrograph of the middle level of the root canal rinsed with (a) $0.2 \%$ chitosan showing some open dentinal tubules and the rest were partially closed with smear plug. Few scattered debris particles are visible (score 2), (b) $1 \%$ chitosan showing open dentinal tubules with very few scattered debris particles (score 1), (c) $2 \%$ chitosan showing open dentinal tubules with very few scattered debris particles (score1), (d) 17\% EDTA showing open dentinal tubules (score1) and (e) saline showing the entire root canal wall covered with a homogenous smear layer (score 4) 


\section{Comparison of smear layer scores within each tested group:(Table 1)}

There was a statistically significant difference among the three levels (coronal, middle, apical) in the mean scores of smear layer. The apical level had the statistically significant highest mean score of smear layer compared to the middle and coronal levels. However, there was no statistical significant difference between the middle and coronal levels in groups I, II,IV,Va $(0.2 \%$ chitosan, $1 \%$ chitosan, $17 \%$ EDTA and saline respectively).

Regarding group III ( $2 \%$ chitosan), the apical level had the statistically significant highest mean score of smear layer compared to the middle level. However, there was no statistical significant difference between the apical and coronal levels.

\section{B. calcium content results}

Comparison of the calcium content among the tested groups: (Table 2, Fig.3)

Regarding the calcium content, the highest mean calcium content was recorded in specimen treated

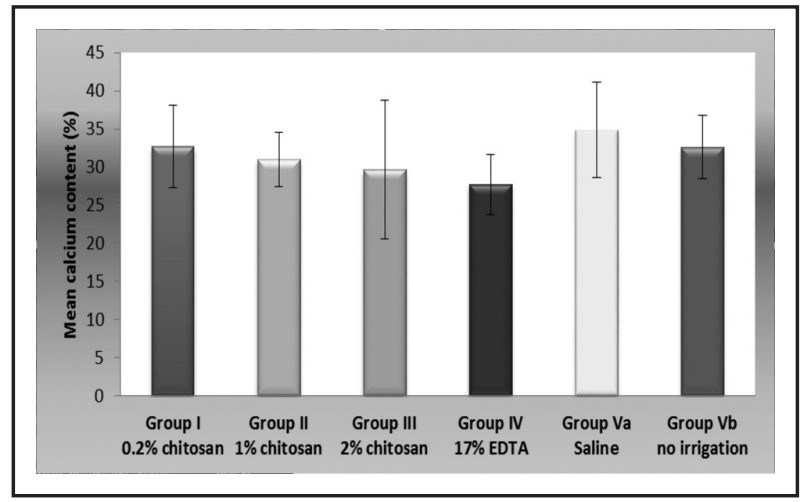

Fig. (3): A bar chart comparing the mean calcium content and standard deviation among $0.2 \%$ chitosan, $1 \%$ chitosan, $2 \%$ chitosan, $17 \%$ EDTA, saline group and group without irrigation.

with saline followed by specimens treated with $0.2 \%$ chitosan followed by specimens that did not receive any irrigation followed by specimens treated with $1 \%$ chitosan followed with $2 \%$ chitosan. The lowest mean calcium content was recorded in specimens treated with $17 \%$ EDTA. However, there was no statistical significant difference among the tested groups in the mean calcium content $(\mathrm{P}>0.05)$.

Table (2): Descriptive analysis of the calcium content of all tested groups.

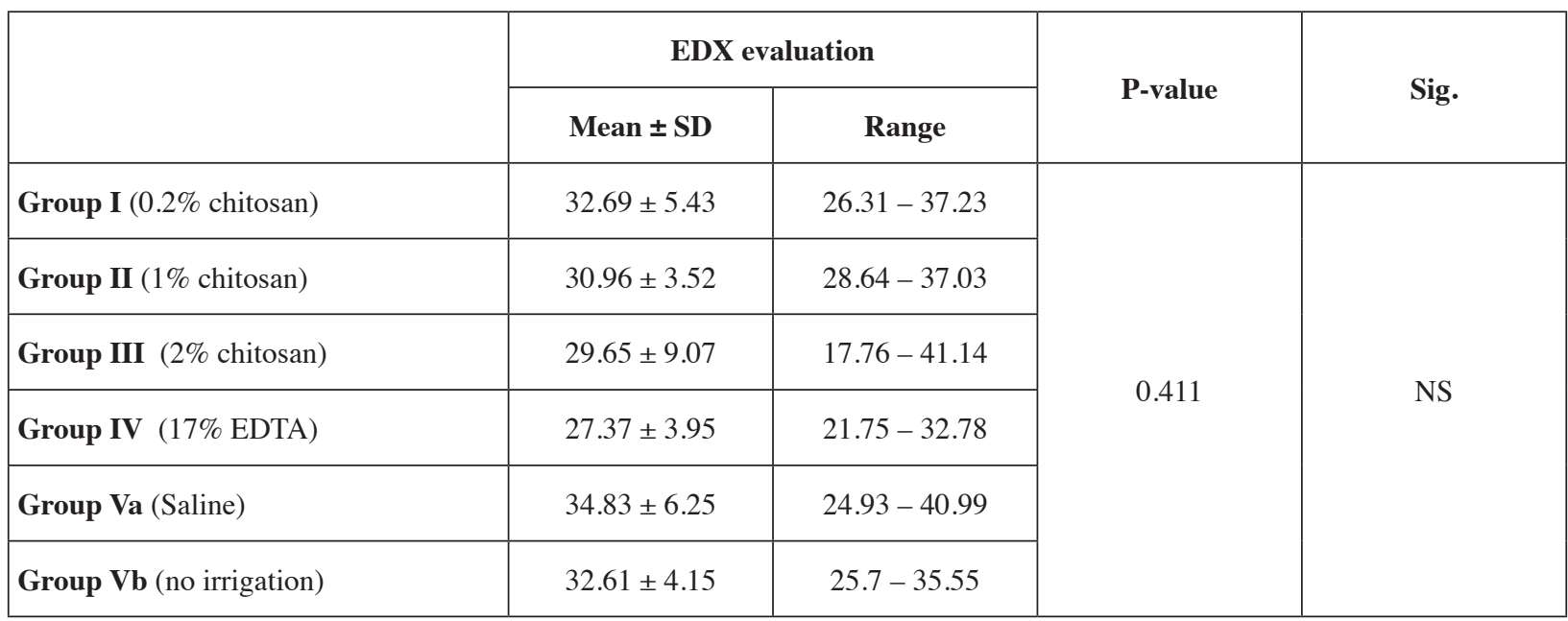




\section{DISCUSSION}

The essential for endodontic success requires removal of vital and necrotic remnants of pulp tissues and microorganisms from the root canal system, which could be achieved through chemomechanical debridement. Smear layer removal has been recommended by several authors as it is crucial for long-term success of root canal treatment (2). Therefore, the aim of the present study was directed to evaluate the effect of different concentrations of chitosan as final rinse on removing smear layer using scanning electron microscope (SEM) and quantify the calcium content of intraradicular dentin after being treated with chitosan using energy dispersive X-ray microanalyzer (EDX).

The efficiency of chitosan for smear layer removal could be explained by the fact that, chitosan is hydrophilic in nature which favors its intimate contact with root canal dentin and its adsorption to root canal wall. Additionally it has large number of free hydroxyl and amino groups that make it cationic in nature which is responsible for the ionic interaction between the dentin calcium ions and the chelating agent ${ }^{(14)}$. Two theories explain the possible chelating mechanism of chitosan; one theory, known as the bridge model, states that two or more amino groups of a chain of chitosan bind to the same metal ion ${ }^{(15)}$. The second theory supports that only one amino group of the structure of the substance is involved in the binding, which is the metal ion "anchored" to the amino group ${ }^{(14)}$.

In the current study, chitosan even at the lowest concentration $(0.2 \%)$ was capable of adequately remove the smear layer from the dentin surface at the coronal level. This finding was consistent with previous study ${ }^{(11)}$ and disagree with a recent study, which reported that $0.2 \%$ chitosan was ineffective in removing the smear layer in the three regions of the root surface ${ }^{(16)}$. This could be attributed to using chitosan solution with less contact time (1 min).

Regarding the middle level, the lower mean smear layer score produced by $2 \%$ chitosan could be attributed to the fact that, the higher the concentration of a solution, the stronger the chelating effect is ${ }^{(17)}$. The concentration of $2 \%$ chitosan is ten times that of $0.2 \%$ concentration, which probably intensified the demineralizing action of $2 \%$ chitosan. Moreover, the $\mathrm{pH}$ of the solution is an important factor to demineralization. In the present study $2 \%$ chitosan showed decrease in the $\mathrm{pH}$ (3.25) compared to that of $0.2 \%$ chitosan (4.6). This might be due to a balance between the decrease in the $\mathrm{pH}$ and increase in the viscosity of the chitosan-organic acid solution caused by the increase in the constituent concentration ${ }^{(18)}$. Additionally, in an acid medium, the amino groups present in the chitosan are protonated $(-\mathrm{NH} 3+)$, resulting in attraction to other molecules for adsorption to root dentin to occur. The formation of complexes between chitosan and metal ions most probably is due to the mechanisms of adsorption, ion exchange and chelation ${ }^{(19)}$.

The lower efficiency of $0.2 \%$ chitosan to clean the middle third reported in this study was in agreement with previous study ${ }^{(16)}$ and disagree with previous study, which revealed that $0.2 \%$ chitosan, $15 \%$ EDTA removed smear layer efficiently from the middle third of the root canal ${ }^{(20,11)}$. These discrepancies might be attributed to differences in the contact time of chitosan (5 minutes). In the other study this discrepancy might be attributed to using different rotary files (Protaper instruments), as it has been shown that, the design of the cutting blade of rotary instruments can affect root canal cleanliness ${ }^{(21)}$.

The low effectiveness of $0.2 \%$ chitosan in cleaning the apical third was in accordance with a recent study ${ }^{(16)}$. On the other hand, the results of the present study was in disagreement with previous studies ${ }^{(10,22)}$. This divergence in results could be explained by the fact that, collection of the solutions used as irrigants for spectrometric analysis, the apices of the specimens were patent. Thus, during the act of irrigation, the solution passed through the entire root canal leading directly into the collection 
tube through the apical foramen. In the other study this discrepancy might be attributed to differences in the contact time of chitosan (5 minutes).

EDTA efficiently removed the smear layer due to its chelating property. This might be attributed to that, EDTA form a stable complex with the calcium ions in dentin. Accordingly, carboxyl groups of the EDTA molecule are ionized, releasing hydrogen atoms that compete with the calcium ions. When all available ions have been bound, equilibrium is formed and no further dissolution takes place ${ }^{(4)}$. Moreover, the organic matrix of dentin may act as a limiting factor in the dissolution of the inorganic component, thus the decalcifying action of EDTA stops ${ }^{(23)}$. Similar chelating effectiveness of $2 \%$ chitosan and 17\% EDTA was in accordance with previous study, which reported that $2 \%$ chitosan was effective in removing the smear layer as $17 \%$ EDTA $^{(24)}$

In general, analysis of the dentinal wall of samples revealed that, they have more smear layer at the apical third compared to the coronal two thirds. This was possibly attributed to the reduction of the diameter of dentinal tubules and the flow ability of the fluid, which were found to be poor in the apical third ${ }^{(25)}$. This was confirmed by a previous study, which concluded that greater amounts of smear layer were found at the apical third of the canal ${ }^{(26)}$.

The highest mean calcium content that recorded in group Va (saline) (saline used as final rinse and $2.6 \%$ sodium hypochlorite solution used during instrumentation) compared to group $\mathrm{Vb}$ (not receive any irrigation) could be explained by the variable effect of $\mathrm{NaOCl}$ as irrigating solution on mineral content of root dentin, where it has been reported that treatment with sodium hypochlorite may causes mineral accumulation in human root dentin ${ }^{(27)}$. Moreover, it has been demonstrated that the use of $2.5 \%$ sodium hypochlorite as irrigation solution, either alone or combined with 17\% EDTA solution significantly increases the $\mathrm{Ca} / \mathrm{P}$ ratio of root dentin ${ }^{(23)}$.
Regarding the lower mean calcium content recorded in specimens treated 17\% EDTA compared to that recorded in specimens treated $0.2 \%$ chitosan, the results was in agreement with previous study ${ }^{(28)}$. However, the results of the current study showed that, there was no statistical significant difference among the tested groups in the mean calcium content. This finding was in accordance with a recent study, which reported that $0.2 \%$ chitosan is equally effective to $17 \%$ EDTA in removing $\mathrm{Ca}$ ions from root dentin ${ }^{(29)}$.

\section{CONCLUSION}

Within the limitations of this study the following could be concluded:

1. Chitosan was capable of adequately removing smear layer from intraradicular dentin when used as final rinse.

2. The concentration of chitosan is influential in smear layer removal from intraradicular dentin, being more effective when used in $1 \%$ and $2 \%$ concentrations.

3. Different concentrations of chitosan did not affect the calcium content of intraradicular dentin.

Further studies are recommended to investigate the effect of $1 \%$ chitosan on dentin microhardness, the surface roughness of root dentin and the adhesion of sealers to the dentin surfaces and cleaning ability of it with different irrigating delivery systems.

\section{REFERENCES}

1. Sen BH, Wesselink PR, Turkun M. The smear layer: a phenomenon in root canal therapy. Int Endod J 1995; 2:141-8.

2. Torabinejad M, Handysides R, Khademi AA, Bakland LK. Clinical implications of the smear layer in endodontics: a review. Oral Surg Oral Med Oral Pathol Oral Radiol Endod 2002; 94:658-66.

3. Zehnder M, Kosicki D, Luder H, Sener B, Waltimo T. Tissue-dissolving capacity and antibacterial effect of buffered and unbuffered hypochlorite solutions, Oral Surg Oral Med Oral Pathol Oral Radiol Endod 2002; 94 :756-62. 
4. Hülsmann M, Heckendorf M, Lennon À. Chelating agents in root canal treatment: mode of action and indications for their use. Int Endod J 2003; 36: 810-30.

5. Jaju S, Prashant P. Newer Root Canal Irrigants in Horizon. Int J Dent 2011, ID 851359:1-9.

6. Senel S, Kas HS, Squier CA. Application of chitosan in dental drug delivery and therapy. From Dietary Supplement to Drug Carrier. 2000; 241-56.

7. Kurita K. Chemistry and application of chitin and chitosan. Polyme Degrad Stabil. 1998; 59: 117-20.

8. Jeon YJ, Shahid F, Kin SK. Preparation of chitin and chitosan oligomers and their applications in physiological functional foods. Food Reviews Inter 2000; 16: 159-76.

9. Silva PV, Guedes DF, Pécora JD, Cruz-Filho AM. Timedependent effects of chitosan on dentin structures. Braz Dent J 2012; 23: 357-61.

10. Silva PV, Guedes DF, Nakadi FV, Pécora JD, Cruz-Filho AM. Chitosan: a new solution for removal of smear layer after root canal instrumentation. Int Endod J 2013; 46:332-8.

11. Darrag AM. Effectiveness of different final irrigation solutions on smear layer removal in intraradicular dentin. Tanta Dent J 2014; 11: 93-9.

12. Praveen M, Aarthi G, Meenapriya PK, Kumar SS, Mohan Kumar NS, Karunakaran JV. A comparative evaluation of intraradicular smear removal efficacy of $2 \%$ chitosan (low molecular weight), $4 \%$ chitosan citrate, and $10 \%$ Citric acid when used as Final rinse in irrigation protocols. A Field emission scanning electron microscope study. J Pharm Bioallied Sci 2017; 9:73-8.

13. Hülsmann M, Rümmelin C, Schäfers F. Root canal cleanliness after preparation with different endodontic handpieces and hand instruments: a comparative SEM investigation. J Endod. 1997; 23:301-6.

14. Domard A. PH and CD measurements on a fully deacetylated chitosan: application to CuII-polymer interactions. Int J Biol Macromol 1987; 9:98-104.

15. Blair HS and Ho TC. Studies in the adsorption and diffusion of ions in chitosan. J Chem Technol Biotechnol 1981; 31:6-10.

16. Vallabhaneni K, Kakarla P, Jogendra Avula SS, ReddyVG, Gowd P.Comparative analyses of smear layer removal using four different irrigant solutions in the primary root canals. A scanning electron microscopic study. J Clin Diagn Res. 2017; 11: 64-7.

17. Reis C, De-Deus G, Leal F, Azevedo É, Filho TC, Paciornik S. Strong effect on dentin after the use of high con- centrations of citric acid: an assessment with co-site optical microscopy and ESEM. Dent Mater 2008; 24:1608-15.

18. Chen R.H, Lin WC, Lin JH. Effects of pH, ionic strength, and type of anion on the rheological properties of chitosan solutions. Acta Polymer 1994, 45; 41-6.

19. Rhazi M, Desbrières J, Tolaimate A, Rinaudo M, Vottero $\mathrm{P}$, Alagui A. Influence of the nature of the metal ions on the complexation with chitosan. Application to the treatment of liquid waste. Eur Polym J 2002; 38:1523-30.

20. Pimenta JA, Zaparolli D, Pécora JD, Cruz-Filho AM. Chitosan: effect of a new chelating agent on the microhardness of root dentin. Braz Dent J 2012; 23: 212-7.

21. Jeon IS, Spangberg LS, Yoon TC, Kazemi RB, Kum KY. Smear layer production by 3 rotary reamers with different cutting blade designs in straight root canals: a scanning electron microscopic study. Oral Surg Oral Med Oral Pathol Oral Radiol Endod 2003; 96:601-7.

22. Neha S, Khurramuddin M, Shekar K, Smitha R, Dola B , Singh V. Effect of different irrigation regimens on smear layer removal in human root dentin an in vitro study. Asian J health scien 2017; 4:31-37.

23. Dogan $\mathrm{H}$ and Calt $\mathrm{S}$. Effects of chelating agents and sodium hypochloride on mineral content of root dentin. J Endod 2001; 27:578-80.

24. Fawzy MI. Scanning electron microscopic evaluation of the effectiveness of chitosan solution in smear layer removal. Egy Dent J 2011; 57:419-24.

25. Wu L, Mu Y, Deng X, Zhang S, Zhou D. Comparison of the effect of four decalcifying agents Combined with $60 \mathrm{C}$ $3 \%$ sodium hypochlorite on smear layer removal. J Endod 2012; 38:381-4.

26. Gulabivala K, Ng Y-L, Gilbertson M, Eames I. The fluid mechanics of root canal irrigation. Physiol Meas. 2010; 31:49-84

27. Inaba D, Ruben $\mathrm{J}$,Takagi O, Arends J. Effect of sodium hypochlorite treatment on reminerization of human root dentin in vitro. Caries Res 1996; 30:218-24.

33. Mathew SP, Pai VS, Usha G, Nadig RR .Comparative evaluation of smear layer removal by chitosan and ethylenediaminetetraacetic acid when used as irrigant and its effect on root dentin: An in vitro atomic force microscopic and energy-dispersive X-ray analysis. J Conserv Dent 2017; 20: 245-50.

34. Bastawy HA and Ezzat R. Impact of chitosan as chelating agent on microhardness and mineral content of intraradicular dentin. Al Azhar Dent J for Girls 2016; 1: 4879-89. 